\title{
The spectrum of benign breast lesions - A study in Tertiary Care Hospital
}

\author{
Author \\ Dr Abbadi Venkat Mohan Reddy \\ Associate Professor, Department of General Surgery, Prathima Institute of Medical Sciences, \\ Naganoor, Karimnagar \\ *Corresponding Author \\ Dr Abbadi Venkat Mohan Reddy
}

\begin{abstract}
Benign Breast Disease is primarily seen in the reproductive period of life. They are largely hormoneinduced. So that after menopause and cessation of ovulation, a dramatic decrease in the incidence is seen. The study aimed to find the incidence of benign breast diseases presenting to our Tertiary Care Hospital. Methods: This cross-sectional prospective study was done in the Department of General Surgery, Prathima Institute of Medical Sciences, Karimnagar. A detailed history including Age, Marital status, Socio-economic status, Occupation, history presenting complaints, menstrual history, and the relation of complaints to menstruation was done. Obstetric history, Lactation history, number of babies fed, past history of similar complaints, family history, and personal history was obtained. All the information was noted down in the proforma designed for the study. The following investigations were done complete blood picture, USG breast/mammogram, FNAC, and Histopathological examination. Results: The most common presentation was a lump in the breast $84 \%$ of patients were with this clinical finding. There was pain associated with a lump in $56 \%$ cases and $12 \%$ had only pain and pain, lump and fever were found in 12\%. In the present study of 50 cases of benign breast, the disease was studied in which Fibroadenoma constituted $40 \%$ ( $n=20$ cases). Fibroadenomas with fibrocystic diseases constituted $24 \%$ ( $n=12$ cases). Phylloid tumor (Cystosarcoma phyllodes) constituted 12\% ( $n=6$ cases). Breast abscess constituted $12 \%$ (6 cases). Mastitis $8 \%$ ( $n=4$ cases) and Galactocele constituted $4 \%$ ( $n=2$ cases). Conclusion: Benign breast lesions are very common in females. A painless lump in the breast may be the finding. In some cases, lumps may be present with pain or there may be nipple discharge. The younger females are more likely to have benign breast lesions. Fibroadenoma was the benign lesion found in the study. The accuracy of diagnosis was best by histopathology examination. Early diagnosis and proper treatment will prevent morbidity and mortality due to malignant changes in some lesions.

Keywords: Benign Breast Lesions, Tertiary Care Hospital.
\end{abstract}

\section{Introduction}

Breast is an anatomical feature of females with important functions. The concept of female beauty and feminity is incomplete without it. Therefore, it must be in shape and form that is aesthetically acceptable in all situations. It is a significant factor as a female and sexual attractiveness ${ }^{[1]}$. Benign breast lesions constitute a group of heterogeneous disorders including abnormal development, abnormal epithelial and stromal proliferation, inflammatory lesions and neoplasm. Benign lesions are the most common cause of 
breast problems in females. It is ten times more common than breast cancer in the western world [2]. The benign breast lesions hence deserve scrutiny because of their high prevalence and tendency to impact the women's life and chances of carcinomatous changes in certain histological types $^{[3]}$. Management of benign breast lesions is based on the principles of preservation of existing normal tissue as far as possible in contrast to traumatizing mutilating surgeries done for breast cancers. The diagnosis of benign breast lesions is done by a triple assessment which includes clinical examination, imaging like USG/ mammography and pathological examination with FNAC or core needle biopsy. Most of the benign lesions are not generally associated with increased risk for subsequent breast cancers hence, unnecessary surgical procedures can be avoided [4]. Making an early diagnosis after consultation helps in alleviating anxiety due to fear of breast cancer and those with increased risk of malignancy like atypical hyperplasia can be given treatment in the right direction with follow-up. With this background, we in the present study tried to evaluate the incidence and morphological features of benign breast diseases presenting to our tertiary care hospital.

\section{Material and methods}

This cross-sectional prospective study was done in the Department of General Surgery, Prathima Institute of Medical Sciences, Karimnagar. Institutional Ethical committee permission was obtained for the study. Inclusion criteria were all the cases Diagnosed clinically benign Breast Diseases irrespective of age were included in the study. Exclusion criteria were patients with malignant breast lesions. Based on the inclusion and exclusion criteria a total of $\mathrm{N}=50$ patients were studied during the period. A detailed history including Age, Marital status, Socio-economic status, Occupation, history presenting complaints, menstrual history, and the relation of complaints to menstruation was done. Obstetric history, Lactation history, number of babies fed, past history of similar complaints, family history, and personal history was obtained. All the information was noted down in the proforma designed for the study. The following investigations were done complete blood picture, USG breast/mammogram, FNAC, and Histopathological examination. Surgery was done under local or general anesthesia, depending upon the duration of surgery and the size of the lump. Excised lump after the macroscopic examination was sent for histopathological examination. The wound was closed either with subcuticular/simple/ mattress sutures. Postoperatively the patient was given antibiotics. Sutures were removed after appropriate healing. All the patients were asked to come for follow up to know the histopathological reports. Patients with histopathological examination diagnosis were treated accordingly and our diagnosis was correlated. Patients with some other complaints in the follow-up were also treated accordingly.

\section{Results}

The youngest patient in the present study is 15 years and the oldest patient is 50 years. Most of the patients were in the age range of 21-30 years. On the whole benign breast disease resented in 2nd and 3rd decades of life (40\%).

Table 1: showing the incidence of disease and distribution in the study

\begin{tabular}{|l|c|c|c|c|c|}
\hline \multirow{2}{*}{ Lesions } & \multicolumn{4}{|c|}{ Age group in years } & Total (\%) \\
\cline { 2 - 5 } & $11-20$ & $21-30$ & $31-40$ & $41-50$ & \\
\hline Fibroadenoma & 2 & 10 & 6 & 2 & $20(40)$ \\
\hline Fibradenosis with fibrocystic disease & 2 & 4 & 6 & 0 & $12(24)$ \\
\hline Cysto Sarcoma phylloid & 0 & 2 & 2 & 2 & $6(12)$ \\
\hline Breast abscess & 2 & 2 & 2 & 0 & $6(12)$ \\
\hline Mastitis & 0 & 0 & 2 & 2 & $4(8)$ \\
\hline Galactocele & 0 & 2 & 0 & 0 & $2(6)$ \\
\hline
\end{tabular}




\section{JMSCR Vol||07||Issue||11||Page 872-876||November}

The most common presentation was a lump in the breast $84 \%$ of patients were with this clinical finding. There was pain associated with a lump in $56 \%$ cases and $12 \%$ had only pain and pain, lump and fever were found in $12 \%$.

Table 2: Mode of presentation

\begin{tabular}{|l|c|c|c|}
\hline Sl. No & Symptoms & Frequency & Percentage \\
\hline 1. & Lump & 42 & 84 \\
\hline 2. & Lump with pain & 28 & 56 \\
\hline 3. & Pain & 6 & 12 \\
\hline 4. & Lump, pain, and fever & 6 & 12 \\
\hline
\end{tabular}

The most commonly involved quadrant in the breast lesions was the upper and outer in $n=20$ $(40 \%)$ of cases followed by lower and inner in $\mathrm{n}=12(24 \%)$ and the whole breast was involved in $\mathrm{n}=10(20 \%)$ of cases.

Table 3: Showing the breast quadrants involved in lesions

\begin{tabular}{|l|c|c|c|}
\hline Sl. No & Involved Quadrant & No of cases & Percentage \\
\hline 1 & Upper and Outer & 20 & 40 \\
\hline 2 & Lower and outer & 04 & 8 \\
\hline 3 & Upper and inner & 04 & 8 \\
\hline 4 & Lower and inner & 12 & 24 \\
\hline 5 & Whole breast & 10 & 20 \\
\hline \multicolumn{2}{|c|}{ Total } & 50 & 100 \\
\hline
\end{tabular}

Table 4: sides of the breast involved in the lesions

\begin{tabular}{|l|c|c|c|}
$\begin{array}{l}\text { Sl. } \\
\text { No }\end{array}$ & Side Involved & $\begin{array}{c}\text { No of } \\
\text { Cases }\end{array}$ & Percentage \\
\hline 1 & Right side & 34 & 68 \\
\hline 2 & Left Side & 14 & 28 \\
\hline 3 & Bilateral & 02 & 04 \\
\hline \multicolumn{2}{|l|}{ Total } & 50 & 100 \\
\hline
\end{tabular}

In the present study, the duration of the symptoms was studied, in which most of the cases presented between duration of $1-6$ months (32\%) the other details are given in table 5.

Table 5: Duration of symptoms of cases in the study

\begin{tabular}{|l|c|c|c|}
\hline Sl. No & Side Involved & $\begin{array}{c}\text { No of } \\
\text { Cases }\end{array}$ & Percentage \\
\hline 1 & $<1$ month & 10 & 20 \\
\hline 2 & $1-6$ months & 16 & 32 \\
\hline 3 & $6-12$ months & 14 & 28 \\
\hline 4 & $>1$ year & 10 & 20 \\
\hline \multicolumn{2}{|c|}{ Total } & 50 & 100 \\
\hline
\end{tabular}

In the present study of 50 cases of benign breast, the disease was studied in which Fibroadenoma constituted $40 \%$ ( $n=20$ cases). Fibroadenosis with fibrocystic diseases constituted $24 \%$ ( $\mathrm{n}=12$ cases). Phyllodes tumor (Cystosarcoma phyllodes) constituted $12 \% \quad$ ( $\mathrm{n}=6$ cases). Breast abscess constituted $12 \%$ (6 cases). Mastitis $8 \% \quad(n=4$ cases) and Galactocele constituted $4 \%$ ( $\mathrm{n}=2$ cases)

Table 6: Comparison of Histopathology versus USG Versus FNAC for diagnosis

\begin{tabular}{|l|c|c|c|c|c|c|}
\hline \multirow{2}{*}{ Lesions } & \multicolumn{2}{|c|}{ Histopathology } & \multicolumn{2}{|c|}{ USG } & \multicolumn{2}{c|}{ FNAC } \\
\cline { 2 - 7 } & N & \% & N & \% & N & \% \\
\hline Fibroadenoma & 20 & 40 & 19 & 38 & 20 & 40 \\
\hline Fibradenosis with fibrocystic disease & 12 & 24 & 11 & 22 & 12 & 24 \\
\hline Cysto Sarcoma phyllodes & 06 & 12 & 05 & 10 & 06 & 12 \\
\hline Breast abscess & 06 & 12 & 06 & 12 & 06 & 12 \\
\hline Mastitis & 04 & 08 & 04 & 08 & 04 & 08 \\
\hline Galactocele & 02 & 04 & 02 & 04 & 02 & 04 \\
\hline Total & 50 & 100 & 47 & 94 & 50 & 100 \\
\hline
\end{tabular}

In the present study, all the cases of fibroadenoma were treated by excisional biopsy. $\mathrm{N}=6$ cases of the fibrocystic disease were treated by excisional biopsy and $n=6$ were treated by the conservative method. The $n=6$ cases of cystosarcoma phyllodes which were studied in the series were treated by simple mastectomy. All the cases of breast abscess were treated by incision and drainage procedure. Two cases of mastitis were treated by conservative method, another two cases with excisional biopsy and two cases of Galactocele were also treated by excisional biopsy. 
Table 7: showing the treatment done in benign breast lesions

\begin{tabular}{|l|c|c|c|c|}
\hline Lesions & Excision & $\begin{array}{c}\text { Subcutaneous } \\
\text { Mastectomy }\end{array}$ & $\begin{array}{c}\text { Incision and } \\
\text { drainage }\end{array}$ & Conservative \\
\hline Fibroadenoma & 20 & 00 & 00 & 00 \\
\hline $\begin{array}{l}\text { Fibradenosis with } \\
\text { fibrocystic disease }\end{array}$ & 06 & 00 & 00 & 06 \\
\hline Phyllodes Tumor & 00 & 06 & 00 & 00 \\
\hline Breast abscess & 00 & 00 & 06 & 00 \\
\hline Mastitis & 02 & 00 & 00 & 02 \\
\hline Galactocele & 02 & 00 & 00 & 00 \\
\hline
\end{tabular}

\section{Discussion}

In the present study, the youngest patient was 15 yrs and the eldest was 50 yrs. The common age group affected with Benign breast lesions was 21 - 30 years with $n=18(36 \%)$ patients. This shows that benign breast lesions are fairly common in young adult females. In similar studies across India for benign breast lesions showed that the maximum incidence was in the age of $21-30$ years the observations were correlating with the results of the present study ${ }^{[5-7]}$. The present study showed that the most common quadrant involved in the cases of the present study was upper and outer quadrant. Soji FO et al ${ }^{[6]}$ in their study showed this quadrant was more frequently involved in benign breast lesions. The upper and outer quadrant is an area of the breast where maximum breast mass is located and hence more commonly involved in lesions. In this study, we found the most common side involved with lesions was the right side and this finding is also consistent with findings of the other studies ${ }^{[6,7]}$. In this study, we found a lump in the breast $84 \%$ of patients were with this clinical finding. There was pain associated with a lump in $56 \%$ cases. Chaudhary et al; ${ }^{[9]}$ in their study on benign breast lesions noted the presence of a lump in $39 \%$ of cases, pain in $27.39 \%$ and nipple discharge in $2.49 \%$. Mallikarjuna et $a{ }^{[10]}$ have found the presence of a painless lump in $80 \%$ of cases and $20 \%$ were present with pain and lump. Sagar et al; ${ }^{[11]}$ have found a painless lump in $78.13 \%$ of cases and the rest $21.87 \%$ were painful lumps. In the present study, the common duration of symptoms was within 6 months. These patients who presented earlier helped us not only in treating them at the early stage of the disease, but also to rule out the presence of cancer which is although less common in young has been known to occur. Tibor Dc et al; ${ }^{[12]}$ have also similar findings consistent with the findings of this study. In the present study of 50 cases of Benign Breast Disease, the size of the lesion ranges from $2 \times 2 \mathrm{cms}$ to $12 \times 14 \mathrm{cms}$. In Soji FO et al; study ${ }^{[6]}$ number of lesions varied from $1 \mathrm{~cm}$ to $10 \mathrm{cms}$. The largest lesion in size was diagnosed as phyllodes tumor. In the present study, Fibroadenoma was the most common Benign Breast Disease noted in 20 cases (40\%), which was also consistent with the other studies by Bagale et al; Mallikarjuna et al; Prajapati et al; and Pudale et al $;^{[10,13-15]}$. The next common disease in the present study was Fibroadenosis with Fibrocystic disease in 24\%, Ranghabashyam et ${ }^{;} ;{ }^{[16]}$ have found Fibroadenosis with Fibrocystic disease 14.2\% cases of their study patients. Phyllodes tumor was found in $\mathrm{N}=6(12 \%)$ of cases and Ranghabashyam et $a{ }^{[16]}$ found in $2.3 \%$ of cases. In the present study, all the cases of Fibroadenoma were treated by excisional biopsy using General Anesthesia or Local Anesthesia. $\mathrm{N}=6(12 \%)$ cases of Fibrocystic disease were treated by excision biopsy using General Anesthesia or Local Anesthesia, and other $\mathrm{n}=6(12 \%)$ cases of Fibrocystic disease were treated by conservatively. $\mathrm{N}=6$ cases of Phylloids tumors were treated by simple mastectomy using GA. All the cases $n=6(12 \%)$ of Breast abscess were treated by incision and drainage procedure using GA. $\mathrm{N}=2(4 \%)$ cases of Mastitis were treated by conservatively, another two with excisional biopsy. Two cases of Galactocele were treated by excision biopsy using GA. 


\section{Conclusion}

Benign breast lesions are very common in females. A painless lump in the breast may be the initial finding. In some cases, lumps may be present with pain or there may be nipple discharge. The younger females are more likely to have benign breast lesions. Fibroadenoma was the commonly found benign lesion in this study. The accuracy of diagnosis was best by histopathology examination. Early diagnosis and proper treatment will prevent morbidity and mortality due to malignant changes in some lesions.

Conflict of Interest: None

Source of support: Nil

Ethical Permission: Obtained

\section{References}

1. Bland KI, Beenken S.W, Edward M. The breast. Schwartz's principles of surgery. 8th Edn, New York. McGraw-Hill 2005 453-99.

2. Sangma MBM, Panda K, Dasiah S. A Clinico Pathological Study on Benign Breast Diseases. J Clin Diagn Res. 2013; 7(3):503-06.

3. Prajapati SR, Patel KK, Nanavati M. Histopathological Study of Benign Epithelial Lesions of Breast. International journal of scientific research. 2015;7(4): 2277-79.

4. Felecia Cerrato, Brian I Labow. Diagnosis and management of fibroadenomas in the adolescent breast. Semin Plast Surg 2013; 27(1):23-25.

5. Shukla H.S, Kumar S; Benign Breast Disorders in Non-Western populations; Part II, Benign breast disorders in India; World J. Surg 1989: 13, 746-49.

6. Soji F. Oluwole, Freeman H.P; Analysis of Benign Breast Lesions in Blacks; Am J Surg, 1979: 137.
7. Onukak E.E, Cederiquist RA, Benign breast disorders in Non-Western populations; Part III; Benign breast disorders in Northern Nigeria; World J. Surg 1989: 13,750-52.

8. Rocha PDS, Nadkarni NS, and Menezes S. Fine needle aspiration biopsy and breast lesions and histopathologic correlation; An Analysis of 837 cases in four years; Acta cytol 1997; 41(3): 705-12.

9. Choudhary DN, Baishya AK. An analytical study of benign breast disease. 2016; 6(9):543-45.

10. Mallikarjuna, Maralihalli SS. Clinicopathological study of benign breast disease. 2015; 4(2):39-46.

11. Sagar R, Gaddikeri P, Ramakrishna MK. Analytical study of pattern and presentation of benign breast diseases in patients between the ages group 15 to 35 years. Int J Biomed Res. 2015;6(6):41215.

12. Tibor DE Cholnoky; Benign tumors of the breast, Archives of Surgery 1939; 38.

13. Prajapati SR, Patel KK, Nanavati M. Histopathological Study of Benign Epithelial Lesions of Breast. International journal of scientific research. 2015; 7(4):2277-79.

14. Bagale P, Dravid NV, Bagale S, Ahire N. Clinicopathological Study of Benign Breast Diseases. International Journal of Health Sciences \& Research. 2013;3(2).

15. Pudale S, Tonape SD. A histopathological study of nonmalignant breast lesions. Int $\mathbf{J}$ Res Med Sci. 2015; 3(10):2672-76.

16. Shukla H.S, Kumar S. Benign Breast Disorders in Non-Western populations. Part II, Benign breast disorders in India. World J Surg 1989; 13:746-49. 